\title{
Immunological Aspects of Atherosclerosis
}

\author{
A. KRÁLOVÁ ${ }^{1}$, I. KRÁLOVÁ LESNÁ ${ }^{1}$, R. POLEDNE ${ }^{1}$ \\ ${ }^{1}$ Laboratory for Atherosclerosis Research, Centre of Experimental Medicine, Institute for Clinical \\ and Experimental Medicine, Prague, Czech Republic
}

Received June 26, 2014

Accepted July 8, 2014

\section{Summary}

Atherosclerosis is a degenerative inflammatory disease of the vascular wall, which is characterized by the formation of atherosclerotic plaques that contain lipids, activated smooth muscle cells, immune cells, foam cells, a necrotic core and calcified sites. In atherosclerosis pathology, monocytes and macrophages play the most important role by accumulating redundant $L D L$ particles in their oxidized form and producing proinflammatory cytokines. Atherosclerotic plaque macrophages reveal distinct phenotypes that are distinguished into M1 (proinflammatory) and M2 (anti-inflammatory) macrophages. Numerous environmental signals (cytokines, microbial cell molecules) that are received by macrophages drive their polarization, but it must be determined whether this classification reflects different macrophage subtypes or plasticity and phenotypic tissue changes, but the balance between subsets is crucial. M1 macrophages are dominant in symptomatic atherosclerotic plaques, while M2 macrophages are more frequent in asymptomatic plaques. Nevertheless, a positive correlation of both M1 and M2 macrophages with atherosclerotic lesion severity was also observed.

\section{Key words}

Atherosclerosis • Inflammation • Macrophages • Monocytes

\section{Corresponding author}

A. Králová, Laboratory for Atherosclerosis Research, Centre of Experimental Medicine, Institute for Clinical and Experimental Medicine, Vídeňská 1958, 140 21, Prague, Czech Republic. E-mail: urba@medicon.cz

\section{Introduction}

Atherosclerosis is a degenerative inflammatory disease of the vascular wall, which is clinically manifested in ischemic heart disease, peripheral arterial disease, stroke or sudden death. It is characterized by the formation of atherosclerotic plaques, which contain lipids, activated smooth muscle cells, immune cells, foam cells, a necrotic core and calcified sites (Ross 1999).

The best description of pathological changes is represented by a classification that was published by Stary et al. (1994). In total, six stages of atherosclerotic lesions can be distinguished. The term "early lesions" is sometimes used for type I and II lesions, which are ordinarily already present in childhood. Both type I and II lesions are characterized by small lipid deposits in the arterial intima and minor endothelial changes. Type II is generally referred to as fatty streaks, which are characterized by increases in the number of monocytes, intimal macrophages and foam cells. Fatty streaks do not cross into the arterial lumen and therefore do not affect blood flow (Stary et al. 1994). Type II is the first visible lesion and is characterized by layers of macrophages, foam cells and lipid droplets within the intimal smooth muscle cells. Lipid-laden foam cells are derived mainly from macrophages, but smooth muscle cells and other vascular cells might also be involved (Shashkin et al. 2005). Type III lesions are intermediate and transitional, and they serve as a connection between type II and advanced lesions (Stary et al. 1994). Advanced atherosclerotic lesions can also be divided into three types - IV, V and VI. The type IV lesion is also known as atheroma, and it is characterized by severe intimal 
disorganization caused by the lipid core. Type V lesions are defined by formation of new fibrous connective tissues. Disruptions of the lesion surface, hematoma, hemorrhage and thrombotic deposits can develop in these advanced lesions. Type IV or V lesions with one or more of these features are classified as type VI and may also be referred to as complicated lesions (Stary et al. 1995).

\section{Theories of atherogenesis pathology}

Atherosclerosis pathology research began more than 100 years ago with pioneering German and Russian studies recognizing lipid and inflammatory theories.

Further development of atherosclerosis patholology started in the 1950s by Keys documenting a crucial role of cholesterol concentration.

In 1985 Brown and Goldstein discovered that human cells have low-density lipoprotein (LDL) receptors on cell surfaces that remove cholesterol from the blood. If LDL receptors are not present in sufficient numbers or if genetic defects in LDL receptor structure occur, individuals develop hypercholesterolemia and become at risk for cholesterol related diseases (Goldstein and Brown 1973).

In the 1990s, Virchow's hypothesis was rediscovered by Russell Ross. He formulated the "response to injury" hypothesis (for summary see Ross 1999), which proposed that endothelial damage is the first step in the development of atherosclerotic lesions followed by monocyte and T-cell infiltration into the arterial wall (Jonasson et al. 1986). Although this protective effect of the intact endothelium to modify LDL atherogenic lipoprotein and monocyte influx into arterial wall has been questioned, the pioneer papers of Ross are still frequently referenced, and so-called endothelial dysfunction is supposedly the first sign of preclinical atherosclerosis development. It should be emphasized that under physiological conditions, transcellular LDL particle transport occurs through the endothelium (Rosengren et al. 2002).

Because it is perceived that the main function of monocytes and $\mathrm{T}$ cells is connected to local or systemic infection, several theories that proposed infectious disease as the cause of atherosclerosis appeared in the 1970s (for summary see Epstein et al. 2009). This concept is also supported by experiments performed by Fabricant et al. (1978), who found the presence of arterial lesions in chickens that had been infected with avian herpes virus. These lesions were similar to atherosclerotic changes in humans. Later, several other infectious agents, which might be responsible for atherosclerotic changes in humans, began to appear gradually. These included Chlamydia pneumoniae, Cytomegalovirus, Helicobacter pylori, hepatitis A virus, Porphyromonas gingivalis, Herpes simplex virus and others, which most likely reflect a synergy of multiple infectious agents in the development of atherosclerosis. Antibodies against various pathogens were detected in atherosclerotic plaques. It was observed that in the case of Chlamydia pneumonia, the DNA of which was found in atherosclerotic plaques by polymerase chain reaction (PCR) (Farsak et al. 2000), there is invasion and damage in the arterial wall, increased LDL uptake by macrophages and foam cell formation in the neointima (Kalayoglu and Byrne 1998). Cytomegalovirus infection increased adhesion molecule expression, particularly intercellular adhesion molecule 1 (ICAM-1), on the endothelial surface (Altannavch et al. 2002). The animal model demonstrated cross immune response against heat shock protein 60 (HSP-60) - antigen located on the surface of Helicobacter pylori and on the endothelial cell surface (Ayada et al. 2009).

It is quite clear that viral and bacterial infections likely do not play a direct role in the process of atherosclerosis, as a sharp decrease of myocardial infarction mortality was not related to incidence of different infectious diseases (Dvoř́ková and Poledne 2004). Concurrently, a certain proinflammatory state, which is genetically determined, determines different monocyte behavior (Hubáček et al. 1999). The proinflammatory state marker could be $\mathrm{C}$-reactive protein (CRP), as a number of studies have revealed that inflammatory markers including CRP and proinflammatory cytokines are strong predictors of atherosclerosis and other cardiovascular diseases (Ridker et al. 1998). The importance of the proinflammatory state in atherogenesis was highlighted by findings that increased CRP concentration in the "normal" range represents a significant marker of cardiovascular disease risk (de Maat and Trion 2004). It has been documented that in healthy men who later suffered a myocardial infarction (MI), the concentrations of IgA, IgE and IgG antibodies were significantly higher than in control (Kovannen et al. 1998).

The level of subclinical inflammation might be affected by several genetic and environmental factors including the effect of individual diet. There is considerable evidence that visceral fat in obesity plays 
a crucial role in the inflammatory process as a chronic inflammatory disease with dysregulation of pro- and antiinflammatory cytokine production (for summary see Lyon et al. 2003). It was also documented that a switch from a saturated fatty acid diet to a polyunsaturated fatty acid diet reduced CRP concentration (Králová Lesná et al. 2013). CRP concentration increased with increasing body weight and is related to visceral fat volume (Tintěra et al. 2004). A positive relation of CRP to body mass index (BMI), waist circumference and triglyceride concentration was also documented. Substantial sex differences were observed in the relationship of CRP to age. Whereas it is continuously increasing in men, this increase appears in women only after menopause. A decrease in body weight and visceral fat volume by increased physical activity was accompanied by a significant decrease of CRP levels in young obese women (Poledne et al. 2009).

\section{Monocyte and macrophage participation in atherosclerosis development}

Many studies about atherosclerosis have focused on monocytes and macrophages because they are involved in the inflammatory process (Libby et al. 2013). In atherosclerosis pathology, monocytes and macrophages play the most important role by accumulating of redundant LDL particles in their oxidized form and proinflammatory cytokine production (Fig. 1). Monocyte and macrophage presence in atherosclerotic plaque as well as neutrophils, dendritic cells and mastocytes has been well documented (Galkina and Ley 2007).

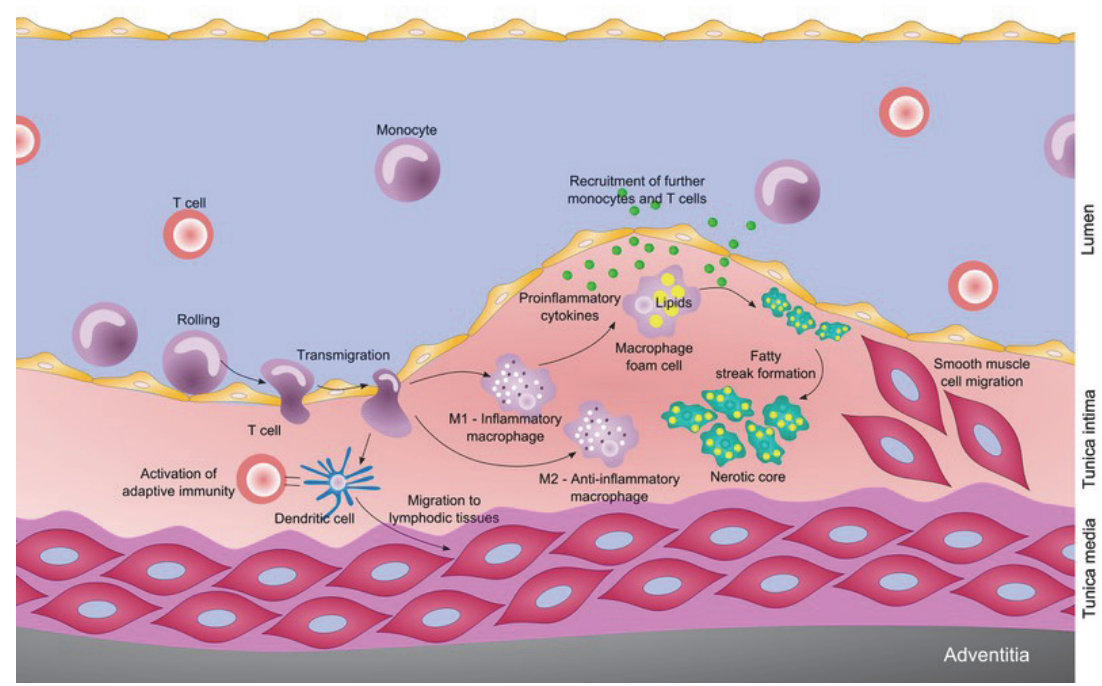

Fig. 1. The role of monocytes in the initiation and progression of atherosclerosis. Following initial injury, endothelial cells become activated and facilitate the rolling, attachment and transmigration of monocytes into the subendothelial space. Monocytes can differentiate into macrophages, which secrete proinflammatory cytokines. Engulfment of lipoprotein particles by macrophages can lead to fatty streak formation, which is the earliest ultrastructural alteration in atherogenesis. The migration of smooth muscle cells from the tunica media into the tunica intima further promotes atherogenic processes. Monocyte-derived cells turn this early lesion into an advanced atherosclerotic plaque that is comprised of a lipid-and macrophage-rich necrotic core that is finally destabilized, leading to plaque rupture (adapted from Heine et al. 2012).
Under physiological conditions, monocytes circulate in the blood, and they are responsible for maintaining homeostasis and removing dead or damaged cells (Auffray et al. 2009). During inflammation, blood monocytes migrate to lymphoid and nonlymphoid tissues in response to tissue-derived signals, where they could be activated by $\mathrm{T}$ cells (Geissman et al. 2008). Monocytes can differentiate into dendritic cells and macrophages which can phagocytose damaged cells and toxic molecules and produce cytokines (Tacke and Randolph 2006).

All of these adhesive and phagocytic processes are described in detail. The process starts with monocyte adhesion to the arterial endothelium. Some studies suggest the importance of ICAM-1 (Poston et al. 1992) and vascular cell adhesion protein - 1 (VCAM-1) (Cybulsky and Gimbrone 1991) expressed on endothelial cells for the interaction of monocytes with the endothelium.

Monocyte interactions with the arterial endothelium are most likely also induced by certain proatherosclerotic stimuli such as tumor necrosis factor (TNF), interleukin-1 $\beta$ (IL-1 $\beta$ ), angiotensin II and oxidized LDL (Álvarez et al. 2004). The abovementioned risk factors may contribute to atherosclerosis development by initiating the inflammatory response and thereby trigger fibroproliferative inflammation.

An important molecule that regulates migration and infiltration into the subendothelial space of a damaged artery is monocyte chemoattractant protein 1 
(MCP-1). Both MCP-1 and its receptor C-C chemokine receptor type 2 (CCR2) are induced and involved in various pathologies. Increased plasma levels of MCP-1 could constitute a risk factor in atherosclerosis development (Gosling et al. 1999). Mice deficient for MCP-1 or its receptor are resistant to atherosclerosis development (Boring et al. 1998).

Regarding the scavenger receptors expression it was shown, that increased scavenger receptors expression on the macrophages surface ( $\mathrm{SR}-\mathrm{A}$ and $\mathrm{SR}-\mathrm{B}$ ) leads to oxidized LDL uptake (Kunjathoor et al. 2002). During short-term exposure to excess lipids there are mechanisms maintaining control over LDL. These mechanisms include storage in lipid droplets, $\beta$-oxidation and cholesterol efflux. Prolonged exposure leads to failure of these mechanisms and various lipotoxic events (Tabas 2002). After transmigration to the subendothelial space, monocytes are transformed into macrophages under the influence of some stimuls from surrounding tissue.

In addition, macrophage activation through their Toll-like receptors (TLRs) produces a number of inflammatory cytokines, particularly IL- $1 \beta$, TNF- $\alpha$ and MCP-1 into the extracellular matrix, which recruits more macrophages. Saturated fatty acids can also signal through TLR-2 and TLR-4 on macrophages in vitro and induce pro-inflammatory gene expression (Shi et al. 2006).

Macrophage egress is also a well-regulated process in which chemokine (C-C motif) ligand 19 (CCL19) and chemokine (C-C motif) ligand 21 (CCL21) play the most important role. Chemokines CCL19 and CCL21 and their receptor on macrophages C-C chemokine receptor type 7 (CCR7) are responsible for macrophage outflow from atherosclerotic lesions in hypercholesterolemia (Trogan et al. 2006). Netrin-1, which is important for neuronal guidance, is a molecule that inhibits macrophage egress from atherosclerotic plaques. During hypercholesterolemia, netrin-1 activates netrin receptor Unc5b on activated macrophages and inhibits macrophage outflow from atherosclerotic plaques. Genetic deletion of netrin-1 enhances macrophage egress from atherosclerotic plaques (van Gils et al. 2012).

It was further demonstrated that statin therapy can promote atherosclerosis regression via activation of the CCR7-dependent emigration pathway in macrophages (Feig et al. 2011).

Foam cells and other cells may significantly contribute to the formation of advanced atherosclerotic plaques that are susceptible to rupture. Necrotic death of foam cells has often resulted in release of intracellular components, leading to chronic inflammation (Baker et al. 2011). Subsequently, smooth muscle cells migrate into the atherosclerotic plaque and thus contribute to its development and subsequent rupture (Moore and Tabas 2011). Ruptured plaques have several histomorphological features that are different from stable plaques. Plaques that rupture tend to have a large lipid core, inflammatory cell infiltration of the fibrous cap and adventitia, and a thin cap depleted of smooth muscle cells. Depletion of matrix components from the fibrous cap caused by an imbalance between synthesis and breakdown leads to cap thinning (Ravn and Falk 1999). If the plaque ruptures, the thrombogenic lesion core is exposed to blood in the arterial lumen. Then, platelet adhesion and activation initiates the formation of an arterial thrombus.

Atherosclerotic plaque stability and vulnerability is also influenced by the activity of matrix metalloproteinases (MMPs), which are produced by inflammatory cells in atherosclerosis pathogenesis, as focally increased expression of several MMPs and MMP activity have been observed in experimental models of atherosclerosis (Brown et al. 1995). MMP activity may contribute to atherosclerosis pathogenesis by facilitating vascular smooth muscle cell migration through the internal elastic lamina into the intima of the vessel wall, where they proliferate and contribute to plaque formation (Ravn and Falk 1999).

Some studies suggest that diffuse intimal thickening is present in human arteries before atherosclerosis develops. Diffuse intimal thickening is believed to be related to atherosclerosis because it is consistently present in atherosclerosis-prone arteries, such as coronary arteries and abdominal aorta. Diffuse intimal thickening can be a depot for extracellular lipids in the earliest initial stages of atherosclerosis (type I lesions). It is assumed that extracellular proteoglycans located in diffuse intimal thickening play an important role in early stages of atherosclerosis by binding atherogenic lipoproteins followed by macrophages infiltration into the deeper layer of intima and forming of foam cells (for summary see Nakashima et al. 2008).

In addition to innate immune cells in atherosclerotic plaques, there are also adaptive immune cells from which CD4+ cells (particularly Th1 cells $\mathrm{T}$ helper cells) are the predominant subpopulation. Th1 cells enhance the proinflammatory characteristics of 
atherosclerosis by producing interferon- $\gamma$ (IFN- $\gamma$ ) and soluble CD40 ligand (CD40L). Presently, B lymphocytes have not been documented in the atherosclerotic plaque, although autoantibodies have been found (for summary see Carbone et al. 2013).

\section{Heterogeneity in monocyte subpopulation in atherosclerosis}

In peripheral blood monocytes represent heterogenous population differing in their phenotypes and functions. They can be divided into functional subsets on the basis of their expression of CD14 and CD16 receptors. CD14 is an assistant receptor for bond of the lipopolysaccharide and CD16 represents a low affinity receptor for Fc parts of IgG antibody.

CD14+CD16- cells correspond with "classical" monocytes. These monocytes, which represent 85-90\% of monocytes in healthy subjects (Passlick et al. 1989), are characterizied by high phagocytic activity, they produce proinflammatory cytokines, and the migration of this subset strongly depends on MCP-1, which is produced by resident macrophages (Swirski et al. 2007).

CD14+CD16+ monocytes represent a minor population that can produce proinflammatory cytokines, but demonstrate lower scavenger receptor expression and higher antigen presenting capacity, do not express MCP-1 receptor and depend on fractalkine for migration into the subendothelial space. On the basis of CD14 expression, two groups of CD14+CD16+ monocytes can be further distinguished as $\mathrm{CD} 14++\mathrm{CD} 16+$ and $\mathrm{CD} 14+\mathrm{CD} 16+$. CD14++CD16+ monocytes (3-9\% of peripheral blood monocytes) are characterized by a combination of some markers typical for mature dendritic cells such as high production of IL-12, high expression of HLA-DR, CD11c and costimulatory molecule CD86. They maintain high expression of CD14 and high phagocytic activity (GrageGriebenow et al. 2001). CD14+CD16+ monocytes (6-13\% of peripheral blood monocytes) are similar to mature tissue macrophages but they share some characteristics of dendritic cells. They are characterized by high expression of MHC I. and MHC II. molecules and antigen presenting capacity (Ziegler-Heitbrock et al. 1993).

The clinical significance of these monocyte subsets and their biological role in atherosclerosis pathogenesis is still under investigation, as correlations of monocyte subsets with clinical signs of atherosclerosis are not consistent (Dopheide et al. 2012). A very interesting publication demonstrated that monocyte subpopulations can be influenced by cardiovascular risk factors (Hristov et al. 2010). In this study, subjects with a lower number of coronary artery disease risk factors had a higher ratio of CD14+CD16+/CD14++CD16+ monocytes compared with high-risk patients. Recently, the role of blood monocytes in atherosclerosis pathogenesis has been reviewed (Jaipersad et al. 2014). However, whether blood monocyte subsets reflect their participation in atherogenesis pathogenesis in the subendothelial space remains unclear.

Atherosclerotic plaque macrophages reveal distinct phenotypes that were distinguished into M1 (classically activated, proinflammatory) and M2 (alternatively activated, anti-inflammatory). M1 macrophages produce large amount of proinflammatory cytokines. Because of production of TNF- $\alpha$, IL-1 $\beta$ and increased NO synthetase activity, M1 macrophages contribute to antimicrobial mechanisms activation (Hesse et al. 2001).

M2 macrophages can be further divided into three subsets based on their different function: macrophages involved in the healing process, regulatory macrophages and macrophages associated with tumor (Mosser 2003).

Numerous environmental signals (cytokines, microbial cell molecules, oxidative stress) received by macrophages drive their polarization, but it must be determined whether this classification reflects different macrophage subtypes or plasticity and phenotypic tissue changes, but the balance between subsets is crucial. Recent work (Cho et al. 2013) has demonstrated that M1 macrophages are dominant in symptomatic atherosclerotic plaques, while M2 macrophages are more frequent in asymptomatic plaques. Other authors (Stöger et al. 2012) found positive correlation of both M1 and M2 macrophages with atherosclerotic lesion severity.

\section{Conclusion}

Although a causal link between LDL cholesterol and atherosclerosis had been demonstrated (for example, by a significant decrease in atherosclerosis mortality after LDL cholesterol was decreased by statin treatment), the picture of atherosclerosis pathology is complete only after immunological influence is included. Although not all details of proinflammatory status regulation have been defined completely, the pivotal role of monocytes and macrophages in this pathology is clear.

Further research is necessary to understand all of 
the detailed steps in proinflammatory processes in the subendothelial space and a genetic predisposition to myocardial infarction and stroke.

\section{Acknowledgement}

The work was supported by the grant No. NT140093/2013 from the Internal Grant Agency of the Ministry of Health of the Czech Republic.

\section{Conflict of Interest}

There is no conflict of interest.

\section{References}

ALTANNAVCH TS, ROUBALOVÁ K, KUČERA P, JUZOVÁ O, ANDEL M: Effect of human cytomegalovirus and glucose on adhesion molecules expression in cultured human endothelial cells. Acta Virol 46: 183-186, 2002.

ÁlVAREZ A, CERDÁ-NICOLÁS M, NAIM ABU NABAH Y, MATA M, ISSEKUTZ AC, PANÉS J, LOBB RR, SANZ MJ: Direct evidence of leukocyte adhesion in arterioles by angiotensin II. Blood 104: 402-408, 2004.

AUFFRAY C, SIEWEKE MH, GEISSMANN F: Blood monocytes: development, heterogeneity, and relationship with dendritic cells. Annu Rev Immunol 27: 669-692, 2009.

AYADA K, YOKOTA K, KOBAYASHI K, SHOENFELD Y, MATSUURA E, OGUMA K: Chronic infections and atherosclerosis. Clin Rev Allergy Immunol 37: 44-48, 2009.

BAKER RG, HAYDEN MS, GHOSH S: NF-кB, inflammation, and metabolic disease. Cell Metab 13: 11-22, 2011.

BORING L, GOSLING J, CLEARY M, CHARO I: Decreased lesion formation in CCR2-/- mice reveals a role for chemokines in the initiation of atherosclerosis. Nature 394: 894-897, 1998.

BROWN DL, HIBBS MS, KEARNEY M, LOUSHIN C, ISNER JM: Identification of 92-kD gelatinase in human coronary atherosclerotic lesions: association of active enzyme synthesis with unstable angina. Circulation 91: 2125-2131, 1995.

CARBONE F, NENCIONI A, MACH F, VUILLEUMIER N, MONTECUCCO F: Evidence on the pathogenic role of auto-antibodies in acute cardiovascular diseases. Thromb Haemost 109: 854-868, 2013.

CHO KY, MIYOSHI H, KURODA S, YASUDA H, KAMIYAMA K, NAKAGAWARA J, TAKIGAMI M, KONDO T, ATSUMI T: The phenotype of infiltrating macrophages influences arteriosclerotic plaque vulnerability in the carotid artery. J Stroke Cerebrovasc Dis 22: 910-918, 2013.

CYBULSKY MI, GIMBRONE MA JR: Endothelial expression of a mononuclear leukocyte adhesion molecule during atherogenesis. Science 251: 788-791, 1991.

DE MAAT MPM, TRION A: C-reactive protein as a risk factor versus risk marker. Curr Opin Lipidol 15: 651-657, 2004.

DOPHEIDE JF, OBST V, DOPPLER C, RADMACHER MC, SCHEER M, RADSAK MP, GORI T, WARNHOLTZ A, FOTTNER C, DAIBER A, MÜNZEL T, ESPINOLA-KLEIN C: Phenotypic characterisation of proinflammatory monocytes and dendritic cells in peripheral arterial disease. Thromb Haemost 108: 1198-1207, 2012.

DVOŘÁKOVÁ A, POLEDNE R: The incidence of infectious disease and changes in the mortality of atherosclerosisrelated complications in the Czech population over the past two decades. Eur J Epidemiol 19: 707-710, 2004.

EPSTEIN SE, ZHU J, NAJAFI AH, BURNETT MS: Insights into the role of infection in atherogenesis and in plaque rupture. Circulation 119: 3133-3141, 2009.

FABRICANT CG, FABRICANT J, LITRENTA MM, MINICK CR: Virus-induced atherosclerosis. J Exp Med 148: 335-340, 1978.

FARSAK B, YILDIRIR A, AKYÖN Y, PINAR A, ÖÇ M, BÖKE E, KES S, TOKGÖZOĞLU L: Detection of Chlamydia pneumoniae and Helicobacter pyroli DNA in human atherosclerotic plaques by PCR. J Clin Microbiol 38: 4408-4411, 2000.

FEIG JE, SHANG Y, ROTLLAN N, VENGRENYUK Y, WU C, SHAMIR R, TORRA IP, FERNANDEZHERNANDO C, FISHER EA, GARABEDIAN MJ: Statins promote the regression of atherosclerosis via activation of the CCR7-dependent emigration pathway in macrophages. PLoS One 6: e28534, 2011.

GALKINA E, LEY K: Leukocyte influx in atherosclerosis. Curr Drug Targets 8: 1239-1248, 2007. 
GEISSMAN F, AUFFRAY C, PALFRAMAN R, WIRRIG C, CIOCCA A, CAMPISI L, NARNI-MANCINELLI E, LAUVAU G: Blood monocytes: distinct subsets, how they relate to dendritic cells, and their possible roles in the regulation of T-cell responses. Immunol Cell Biol 86: 398-408, 2008.

GOLDSTEIN JL, BROWN MS: Familial hypercholesterolemia: identification of a defect in the regulation of 3-hydroxy-3-methylglutaryl coenzyme A reductase activity associated with overproduction of cholesterol. Proc Natl Acad Sci USA 70: 2804-2808, 1973.

GOSLING J, SLAYMAKER SGUL, TSENG S, ZLOT CH, YOUNG SG, ROLLINS BJ, CHARO IF: MCP-1 deficiency reduces susceptibility to atherosclerosis in mice that overexpress human apolipoprotein B. $J$ Clin Invest 103: 773-778, 1999.

GRAGE-GRIEBENOW E, FLAD HD, ERNST M: Heterogeneity of human peripheral blood monocyte subsets. J Leukoc Biol 69: 11-20, 2001.

HEINE GH, ORTIZ A, MASSY ZA, LINDHOLM B, WIECEK A, MARTÍNEZ-CASTELAO A, COVIC A, GOLDSMITH D, SÜLEYMANLAR G, LONDON GM, PARATI G, SICARI R, ZOCCALI C, FLISER D, GÉRARD M: Monocyte subpopulations and cardiovascular risk in chronic kidney disease. Nat Rev Nephrol 8: 362-369, 2012.

HESSE M, MODOLELL M, LA FLAMME AC, SCHITO M, FUENTES JM, CHEEVER AW, PEARCE EJ, WYNN TA: Differential regulation of nitric oxide synthase- 2 and arginase-1 by type $1 /$ type 2 cytokines in vivo: granulomatous pathology is shaped by the pattern of L-arginine metabolism. J Immunol 167: 6533-6544, 2001.

HRISTOV M, LEYENDECKER T, SCHUHMANN C, VON HUNDELSHAUSEN P, HEUSSEN N, KEHMEIER E, KRÖTZ F, SOHN HY, KLAUSS V, WEBER C: Circulating monocyte subsets and cardiovascular risk factors in coronary artery disease. Thromb Haemost 104: 412-414, 2010.

HUBÁČEK JA, ROTHE G, PIŤHA J, ŠKODOVÁ Z, STANĚK V, POLEDNE R, SCHMITZ G: C(-260) > T polymorphysm in the promoter of the CD14 monocyte receptor gene as a risk factor for myocardial infarction. Circulation 99: 3218-3220, 1999.

JAIPERSAD AS, LIP GY, SILVERMAN S, SHANTSILA E: The role of monocytes in angiogenesis and atherosclerosis. J Am Coll Cardiol 63: 1-11, 2014.

JONASSON L, HOLM J, SKALLI O, BONDJERS G, HANSSON GK: Regional accumulations of T cells, macrophages, and smooth muscle cells in the human atherosclerotic plaque. Arteriosclerosis 6: 131-138, 1986.

KALAYOGLU MV, BYRNE GI: Induction of macrophage foam cell formation by Chlamydia pneuomoniae. $J$ Infect Dis 177: 725-729, 1998.

KOVANNEN PT, MANTTARI M, PALOSUO T, MANNINEN V, AHO K: Prediction of myocardial infarction in dyslipidemic men by elevated levels of immunoglobulin classes A, E and G, but not M. Arch Intern Med 158: 1434-1439, 1998.

KRÁLOVÁ LESNÁ I, SUCHÁNEK P, BRABCOVÁ E, KOVÁŘ J, MALÍNSKÁ H, POLEDNE R: Effect of different types of dietary fatty acids on subclinical inflammation in humans. Physiol Res 62: 145-152, 2013.

KUNJATHOOR VV, FEBBRAIO M, PODREZ EA, MOORE KJ, ANDERSSON L, KOEHN S, RHEE JS, SILVERSTEIN R, HOFF HF, FREEMAN MW: Scavenger receptors class A-I/II and CD36 are the principal receptors responsible for the uptake of modified low density lipoprotein leading to lipid loading in macrophages. J Biol Chem 277: 49982-49988, 2002.

LIBBY P, NAHRENDORF M, SWIRSKI FK: Monocyte heterogeneity in cardiovascular disease. Semin Immunopathol 35: 553-562, 2013.

LYON CJ, LAW RE, HSUEH WA: Minireview: adiposity, inflammation, and atherogenesis. Endocrinology 144: 21952200, 2003.

MOORE KJ, TABAS I: Macrophages in the pathogenesis of atherosclerosis. Cell 145: 341-355, 2011.

MOSSER DM: The many faces of macrophage activation. J Leukoc Biol 73: 209-212, 2003.

NAKASHIMA Y, WIGHT TN, SUEISHI K: Early atherosclerosis in humans: role of diffuse intimal thickening and extracellular matrix proteoglycans. Cardiovasc Res 79: 14-23, 2008.

PASSLICK B, FLIEGER D, ZIEGLER-HEITBROCK HW: Identification and characterization of a novel monocyte subpopulation in human peripheral blood. Blood 74: 2527-2534, 1989. 
POLEDNE R, LORENZOVÁ A, STÁVEK P, VALENTA Z, HUBÁČEK J, SUCHÁNEK P, PIŤHA J: Proinflammatory status, genetics and atherosclerosis. Physiol Res $\mathbf{5 8}$ (Suppl 2): S111-S118, 2009.

POSTON RN, HASKARD DO, COUCHER JR, GALL NP, JOHNSON-TIDEY RR: Expression of intercellular adhesion molecule-1 in atherosclerotic plaques. Am J Pathol 140: 665-673, 1992.

RAVN HB, FALK E: Histopathology of plaque rupture. Cardiol Clin 17: 263-270, 1999.

RIDKER PM, CUSHMAN M, STAMPFER MJ, TRACY RP, HENNEKENS CH: Plasma concentration of C-reactive protein and risk of developing peripheral vascular disease. Circulation 97: 425-428, 1998.

ROSENGREN BI, AL RAYYES O, RIPPE B. Transendothelial transport of low-density lipoprotein and albumin across the rat peritoneum in vivo: effects of the transcytosis inhibitors NEM and filipin. $J$ Vasc Res 39: 230-237, 2002.

ROSS R: Atherosclerosis-an inflammatory disease. N Engl J Med 340: 115-126, 1999.

SHASHKIN P, DRAGULEV B, LEY K: Macrophage differentiation to foam cells. Curr Pharm Des 11: 3061-3072, 2005.

SHI H, KOKOEVA MV, INOUYE K, TZAMELI I, YIN H, FLIER JS: TLR4 links innate immunity and fatty acidinduced insulin resistance. $J$ Clin Invest 116: 3015-3025, 2006.

STARY HC, CHANDLER AB, GLAGOV S, GUYTON JR, INSULL W JR, ROSENFELD ME, SCHAFFER A, SCHWARTZ CJ, WAGNER WD, WISSLER RW: A definition of initial, fatty streak, and intermediate lesions of atherosclerosis. A report from the Committee on Vascular Lesions of the Council on Arteriosclerosis, American Heart Association. Arterioscler Thromb 14: 840-856, 1994.

STARY HC, CHAIR MD, CHANDLER AB, DINSMORE RE, FUSTER V, GLAGOV S, INSULL W JR, ROSENFELD ME, SCHWARTZ CJ, WAGNER WD, WISSLER RW: A definition of advanced types of atherosclerotic lesions and a histological classification of atherosclerosis. A report from the Committee on Vascular Lesions of the Council on Arteriosclerosis, American Heart Association. Arterioscler Thromb Vasc Biol 15: 1512-1531, 1995.

STÖGER JL, GIJBELS MJ, VAN DER VELDEN S, MANCA M, VAN DER LOOS CM, BIESSEN EA, DAEMEN MJ, LUTGENS E, DE WINTHER MP: Distribution of macrophage polarization markers in human atherosclerosis. Atherosclerosis 225: 461-468, 2012.

SWIRSKI FK, LIBBY P, AIKAWA E, ALCAIDE P, LUSCINSKAS FW, WEISSLEDER R, PITTET MJ: Ly-6Chi monocytes dominate hypercholesterolemia-associated monocytosis and give rise to macrophages in atheromata. J Clin Invest 117: 195-205, 2007.

TABAS I: Consequences of cellular cholesterol accumulation: basic concepts and physiological implications. $J$ Clin Invest 110: 905-911, 2002.

TACKE F, RANDOLPH GJ: Migratory fate and differentiation of blood monocyte subsets. Immunobiology 211: 609-618, 2006.

TINTĚRA J, HARANTOVÁ P, SUCHÁNEK P, DVOŘ́ÁKOVÁ A, ADAMOVÁ M, HÁJEK M, POLEDNE R: Quantification of intra-abdominal fat during controlled weight reduction: assessment using the watersuppressed breath-hold MRI technique. Physiol Res 53: 229-234, 2004.

TROGAN E, FEIG JE, DOGAN S, ROTHBLAT GH, ANGELI V, TACKE F, RANDOLPH GJ, FISHER EA: Gene expression changes in foam cells and the role of chemokine receptor CCR7 during atherosclerosis regression in ApoE-deficient mice. Proc Natl Acad Sci USA 103: 3781-3786, 2006.

VAN GILS JM, DERBY MC, FERNANDES LR, RAMKHELAWON B, RAY TD, RAYNER KJ, PARATHATH S, DISTEL E, FEIG JL, ALVAREZ-LEITE JI, RAYNER AJ, MCDONALD TO, O'BRIEN KD, STUART LM, FISHER EA, LACY-HULBERT A, MOORE KJ: The neuroimmune guidance cue netrin-1 promotes atherosclerosis by inhibiting the emigration of macrophages from plaques. Nat Immunol 13: 136-143, 2012.

ZIEGLER-HEITBROCK HW, FINGERLE G, STRÖBEL M, SCHRAUT W, STELTER F, SCHÜTT C, PASSLICK B, PFORTE A: The novel subset of CD14+/CD16+ blood monocytes exhibits features of tissue macrophages. Eur J Immunol 23: 2053-2058, 1993. 